\title{
Solid-Phase Synthesis of Peptide-Conjugated Perylene Diimide Bolaamphiphile and Its Application in Photodynamic Therapy
}

Young-O Kim, ${ }^{\dagger}+$ Sung-Jun Park, ${ }^{\dagger}$ Byeong Yeon Jung, ${ }^{\dagger}$ Hyung-Seok Jang, ${ }^{\dagger}$ Seo Keong Choi, ${ }^{\dagger}$ Jaehi Kim $^{\S}$ Sehoon Kim, ${ }^{\| \odot}$ Yong Chae Jung, ${ }^{\ddagger}$ Dong-Sik Shin, ${ }^{\perp}$ and Yoon-Sik Lee ${ }^{* \dagger, \# \oplus \infty}$

${ }^{\dagger}$ School of Chemical and Biological Engineering, Seoul National University, Gwanak-gu, Seoul 08826, Republic of Korea

${ }^{\ddagger}$ Multifunctional Structural Composite Center, Institute of Advanced Composite Materials, Korea Institute of Science and Technology (KIST), Wanju-gun 55324, Jeonbuk, Republic of Korea

${ }^{\S}$ Division of Magnetic Resonance, Korea Basic Science Institute, Ochang 28119, Chung-buk, Republic of Korea

"Center for Theragnosis, Korea Institute of Science and Technology (KIST), 39-1, Hawolgok-dong, Sungbuk-gu, Seoul 02792, Republic of Korea

${ }^{\perp}$ Department of Chemical and Biological Engineering, Sookmyung Women’s University, Yongsan-gu, Seoul 04310, Republic of Korea

\section{Supporting Information}

ABSTRACT: Here, we describe a rapid and efficient synthetic method of peptideconjugated perylene diimide (P-PDI) using solid-phase peptide synthesis (SPPS). Due to severe insolubility of perylene dianhydride (PDA) as a starting material of perylene diimide (PDI), PDA was initially conjugated with amino acids to obtain soluble PDI derivatives. Target peptides were synthesized on a 2-chlorotrityl chloride resin using the SPPS method and then conjugated with the amino acid-appended PDI. Various conditions such as loading levels, reaction times and solvents were optimized for introducing the peptides to both sides of the amino acid-appended PDI. The final P-PDI was obtained with a maximum yield of $80 \%$ in $12 \mathrm{~h}$. Its singlet oxygen-derived phototoxicity on cells was confirmed, which could be applicable to photodynamic therapy.

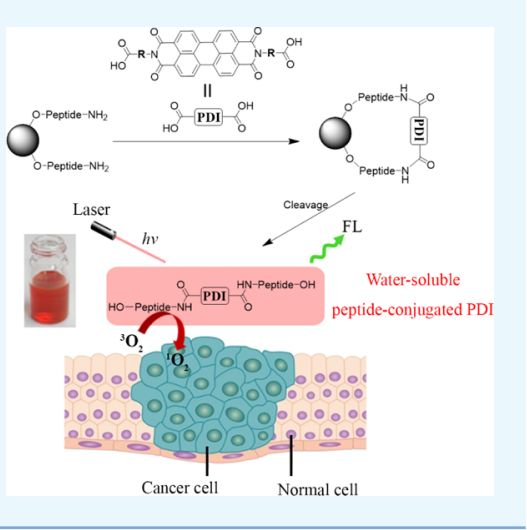

\section{INTRODUCTION}

Photodynamic therapy (PDT) is an efficient method for treating various types of cancers. ${ }^{1-5}$ The viability of a cancer cell is suppressed easily by reactive oxygen species produced by photoactive molecules in the presence of light. Compared to other radiation therapy, the mechanism of PDT allows noninvasive cancer treatment. In PDT, various photosensitizers, such as porphyrin, phthalocyanines, porphycenes, and squaraines, have been used so far. ${ }^{6-9}$ Among them, perylene diimide (PDI) has received considerable attention due to its structural versatility, high fluorescence intensity, and prominent photochemical stability. ${ }^{10,11}$ In particular, water-soluble PDIs have been successfully utilized for biological studies. For example, PDIs functionalized with $\beta$-cyclodextrin or amino acids show improved hydrophilicity and have been applied in bioimaging or for therapeutic purpose. ${ }^{12-14}$ Moreover, PDIs have absorption and emission maxima of above $500 \mathrm{~nm}$, which can minimize a background autofluorescence in cells. ${ }^{15}$

Another promising method for enhancing biological activity is the conjugation of peptides to PDIs where peptides are coupled by incorporating natural or unnatural amino acids sequentially according to their purpose. As peptides have various functions and are highly biocompatible, these properties suit well to the necessary conditions in disease detection and control. In this regard, specially designed bioactive peptideconjugated PDIs can function as promising molecules for bioapplication with multiple purposes.

Methodologically, peptides could be directly condensed to PDA molecules in molten imidazole. ${ }^{16,17}$ However, both the Nterminus of a peptide and the side chain of amino acids can be involved in the condensation reaction, leading to undesired byproducts. To overcome such a problem, Tovar et al. ${ }^{18}$ suggested a method that could conjugate a diverse array of semiconductor molecules with peptides through the solid-phase peptide synthesis (SPPS) method on Wang resin. However, in the case of PDA molecules, an extreme harsh reaction condition $\left(135{ }^{\circ} \mathrm{C}, 26 \mathrm{~h}\right.$, refluxing pyridine), together with the insolubility of PDA and the use of Wang resin as a solid support, has led to a very low yield of less than $<30 \%$.

In this work, we developed a highly efficient detour method to overcome the problems in conjugating peptide to PDI by SPPS. Our method can provide peptide-derived PDI bolaamphiphiles in high yields by using 2 -chlorotrityl chloride (CTC) resin under mild conditions. The method can be

Received: January 9, 2018

Accepted: May 21, 2018

Published: May 31, 2018 
Scheme 1. (a) Synthesis of Amino Acid-Conjugated PDIs. (b) Further Elongation of Peptides to the PDIs on CTC-Resin Through the SPPS Method as a Bolaamphiphile Form

(a)

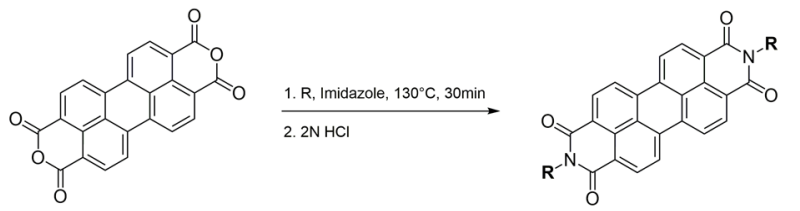<smiles>[R][I-]CC(=O)O</smiles>

(b)
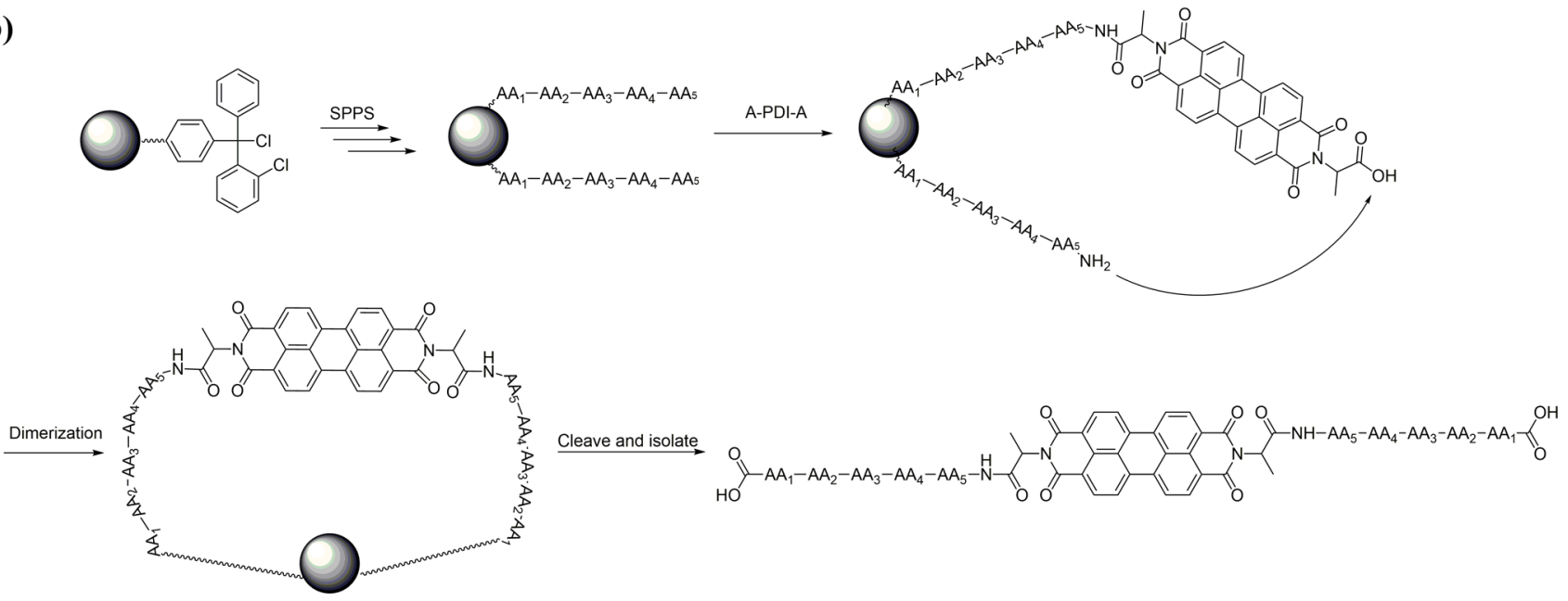

employed in developing various kinds of peptide-conjugated PDIs.

\section{RESULTS AND DISCUSSION}

2.1. Synthesis of Soluble PDI Derivatives. Firstly, insoluble PDA was condensed with $L$-alanine (A), glycine $(\mathrm{G})$, or $\beta$-alanine $(\beta$-A) in molten imidazole to produce soluble PDI derivatives (Scheme 1a). Among the products (PDI- $[\mathrm{A}]_{2}$, PDI- $[\mathrm{G}]_{2}$, and PDI- $[\beta-\mathrm{A}]_{2}$ ), only PDI- $[\mathrm{A}]_{2}$ was readily soluble in $N, N$-dimethylformamide (DMF) and dimethylsulfoxide (DMSO). Both PDI- $[\mathrm{G}]_{2}$ and PDI- $[\beta-\mathrm{A}]_{2}$ showed poor solubility in DMF at room temperature. We assumed that the steric hindrance by the chiral methyl side chain of $L$-alanine overrode the $\pi-\pi$ interaction between perylene moieties, preventing the stacking of the perylene core and increasing the solubility of PDI- $[\mathrm{A}]_{2}$. To figure out the correlation between the $\pi-\pi$ interactions and the solubility of PDI derivatives, we obtained temperature-dependent ${ }^{1} \mathrm{H}$ NMR spectra (Figure S1). With the increase of temperature, the intensity of perylene core-related peaks (8.4-9.0 ppm) of PDI- $[\beta-\mathrm{A}]_{2}$ increased, which means that the solubility of PDI- $[\beta-\mathrm{A}]_{2}$ in DMSO became higher, ${ }^{19}$ while that of PDI- $[\mathrm{G}]_{2}$ remained unchanged. In addition, with increasing temperature, different propensities in the change of chemical shift of the perylene core-related peaks were observed in PDI- $[\mathrm{G}]_{2}$ and PDI- $[\beta-\mathrm{A}]_{2}$; e.g., PDI$[\mathrm{G}]_{2}$ showed a down-field shift, while PDI- $[\beta-\mathrm{A}]_{2}$ showed a slight up-field shift, respectively. The reason for the different propensity of NMR peak shifts depending on temperature is unclear. We believe that the result can provide important information in terms of solubility behavior in the amino acidconjugated PDI. We propose that in PDI- $[G]_{2}$, high temperature induces segregation of the aggregated perylene cores, whereas in PDI- $[\beta-\mathrm{A}]_{2}$, increased temperature leads to solubilization of small-sized $\pi$-stacked molecules, such as dimers, trimers, etc. On the basis of this result, PDI- $[\mathrm{A}]_{2}$, having good solubility in DMF or DMSO, was chosen as a PDI derivative for further peptide coupling reactions.

2.2. Optimization for the Synthesis of PeptideConjugated Perylene Diimide (P-PDI). Bolaamphiphilic PDI peptides were synthesized by the standard SPPS method with a two-step coupling protocol: (1) assembling of bioactive peptides on CTC resin followed by (2) coupling of PDI-[A $]_{2}$ (Scheme $1 \mathrm{~b}$ ). First, 0.5 equiv of PDI-[A $]_{2}$ was coupled to the $\mathrm{N}$-terminus of a peptide, which was assembled on the CTC resin, in DMF overnight at room temperature. Then, the resin was washed and allowed to undergo further coupling reaction without extra addition of PDI- $[\mathrm{A}]_{2}$ to induce maximal dimerization. After acidic cleavage from the resin and trituration with ether, a peptide-conjugated perylene diimide (P-PDI) bolaamphiphile was obtained.

To explore optimal conditions for synthesizing the P-PDI bolaamphiphile, various parameters were controlled, including loading levels, reaction times, and solvents. For the experiment on PDT, we introduced a tripeptide sequence into PDI as a model peptide ligand, specifically Arg-Gly-Asp (RGD). RGD is a well-known cell attaching sequence applied in various biological studies. ${ }^{20-22}$ First, the coupling and dimerization yields between PDI- $[\mathrm{A}]_{2}$ and the peptide on the CTC resin were compared at different reaction times and loading levels (Figure 1). The loading levels were adjusted by controlling the amount of first amino acid coupled to the CTC resin. DMF was selected as a solvent due to its high solubility on PDI- $[\mathrm{A}]_{2}$. After obtaining the RGD peptide-appended PDI from the resin, product yields were compared using high-performance liquid chromatography (HPLC). A peak at around $10.8 \mathrm{~min}$ is the diRGD-appended product, and at around $14.8 \mathrm{~min}$ is the monoRGD-appended PDI, confirmed by electrospray ionization mass spectrometry (ESI-MS) (Figures S2 and S3). As shown in Figure 2, the product yields were monitored by HPLC. Most of the coupling and dimerization reactions were completed within $1 \mathrm{~h}$. As the reaction time proceeded up to 12 


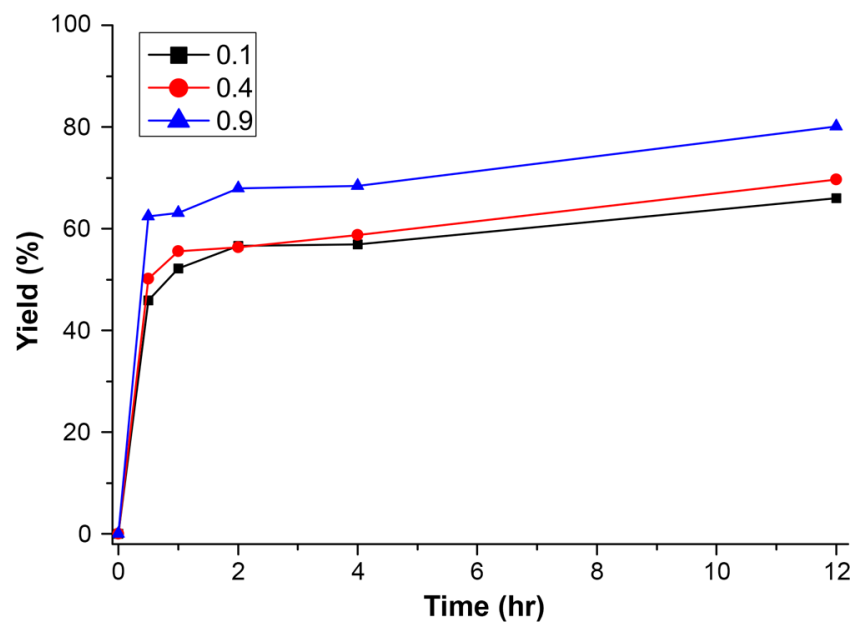

Figure 1. Coupling and dimerization yield vs reaction time depending on the loading level of the CTC resin (black square: $0.1 \mathrm{mmol} / \mathrm{g}$, red circle: $0.4 \mathrm{mmol} / \mathrm{g}$, blue triangle: $0.9 \mathrm{mmol} / \mathrm{g}$ ).
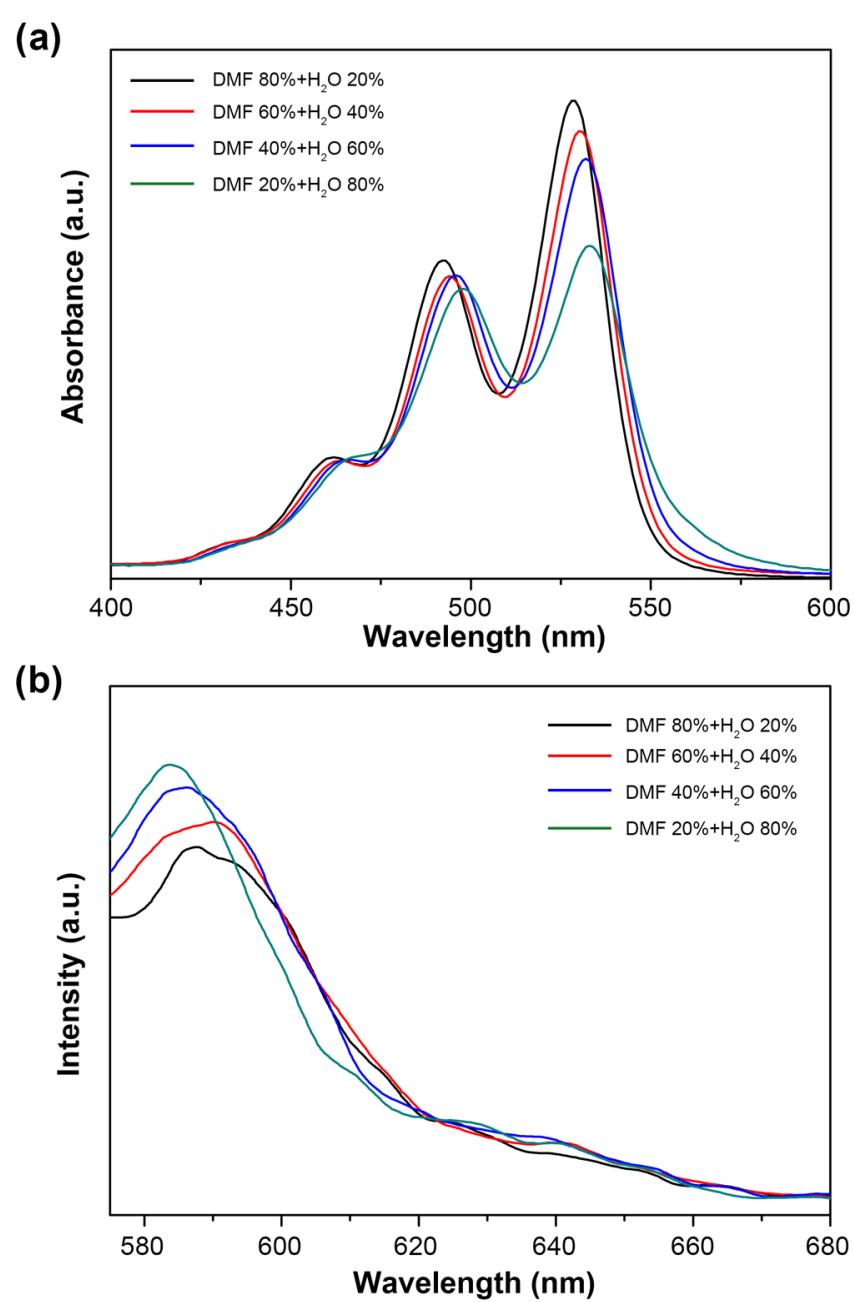

Figure 2. (a) UV spectra and (b) fluorescence spectra $\left(\lambda_{\mathrm{ex}}: 532 \mathrm{~nm}\right)$ of $\mathrm{PDI}-[\mathrm{ARGD}]_{2}$ in the DMF- $\mathrm{H}_{2} \mathrm{O}$ mixture of different ratios.

$\mathrm{h}$, the yields from the reaction with $0.1,0.4$, and $0.9 \mathrm{mmol} / \mathrm{g}$ of peptide loadings increased to about 66,70 , and $80 \%$, respectively. As expected, higher peptide loading favored dimerization, resulting in a higher yield. It can be assumed that dimerization was directly influenced by the concentration of peptides on the resin. Thus, it can be concluded that the longer reaction time and higher peptide loading $(>0.9 \mathrm{mmol} / \mathrm{g})$ provided a favorable result through the symmetric coupling of PDI molecules to the N-terminal of the RGD-conjugated resin.

The solvents can affect the swelling property of the CTC resin, and thus DMF and two other mixed solvents (tetrahydrofuran (THF)/DMF and dichloromethane (DCM)/DMF) were tested. The loading levels and the reaction times were fixed to $0.9 \mathrm{mmol} / \mathrm{g}$ and $1 \mathrm{~h}$, respectively. Within the system of the tested solvents, there were not much difference in the product yield. We expected to observe a direct relationship between the resin swelling and the synthetic efficiency of the P-PDI bolaamphiphile by controlling the distance between the reaction sites within the resin matrix. ${ }^{23}$ As shown in Table 1, although there was a tendency of increasing dimerization yield with an increase in resin swelling, swelling did not appear to be a critical factor in this instance.

Table 1. Swelling Volume of RGD-Conjugated CTC Resin and Dimerization Yield of P-PDI in Various Solvents

\begin{tabular}{lcc}
\hline solvent & swelling volume $(\mathrm{mL} / \mathrm{g})$ & yield $(\%)$ \\
DMF & 2 & 49.5 \\
DMF/THF & 2.2 & 53.1 \\
DMF/MC & 2.4 & 57.1 \\
\hline
\end{tabular}

2.3. Optical Properties of PDI-[ARGD $]_{2}$. Currently there is no standard guideline of an optimal laser source for PDT, and the light sources are usually chosen corresponding to the absorption peaks of a representative dye, porphyrin. ${ }^{24-26}$ In porphyrin, the Soret band $(400-410 \mathrm{~nm})$ shows the highest peak, and the Q band appears from 505 to $635 \mathrm{~nm}$. Both bands have their own pros and cons for PDT, but the longer wavelengths within the $\mathrm{Q}$ bands can penetrate into the skin more deeply. ${ }^{27-29}$ The $Q$ bands require a higher energy level, but this weakness could be overcome in PDI-[ARGD $]_{2}$. UVvis spectra of PDI-[ARGD $]_{2}$ showed three distinct absorption bands at 532, 490, and $460 \mathrm{~nm}$ in the $\mathrm{DMF}-\mathrm{H}_{2} \mathrm{O}$ mixture with the highest peak occurring at $532 \mathrm{~nm}$ (Figure 2a). The $532 \mathrm{~nm}$ band is within the $\mathrm{Q}$ band range, whereby deeper light penetration using lesser energy is possible with PDI-[ARGD $]_{2}$. Since the environment where PDT is conducted is an aquatic condition, the effect of water on the optical properties of PDI$[A R G D]_{2}$ should be confirmed. Upon increasing the amount of water, the absorption peak was shifted to a longer wavelength, and the level of absorbance was decreased. This result suggests that water can partly trigger packing of the PDI core. ${ }^{30}$ Fluorescence spectra also showed a tendency similar to that of the UV-vis spectra (Figure $2 \mathrm{~b}$ ). When the ratio of water increased in the DMF- $\mathrm{H}_{2} \mathrm{O}$ mixed solvent, the intensity of the fluorescence peak decreased slightly and shifted to a longer wavelength. Although slight quenching $(21.5 \%)$ of excitons occurred with the stacking of the PDI core, total quenching could be blocked by the hydrophilic functionalization of PDI. The result suggests that PDI-[ARGD $]_{2}$ can be used as an effective photosensitizer in PDT.

2.4. Singlet Oxygen Generation (SOG) of PDI-[ARGD $]_{2}$. Singlet oxygen $\left({ }^{1} \mathrm{O}_{2}\right)$ generation of PDI-[ARGD $]_{2}$ was estimated by $\rho$-nitrosodimethylaniline (RNO) bleaching assay in the presence of histidine. ${ }^{31}$ The absorbance change of RNO was monitored at $440 \mathrm{~nm}$ under laser irradiation at $532 \mathrm{~nm}$. PDI-[ARGD $]_{2}$ was well dissolved in deionized water to produce ${ }^{1} \mathrm{O}_{2}$ that enabled $\mathrm{RNO}$ bleaching via photochemical 
(a)

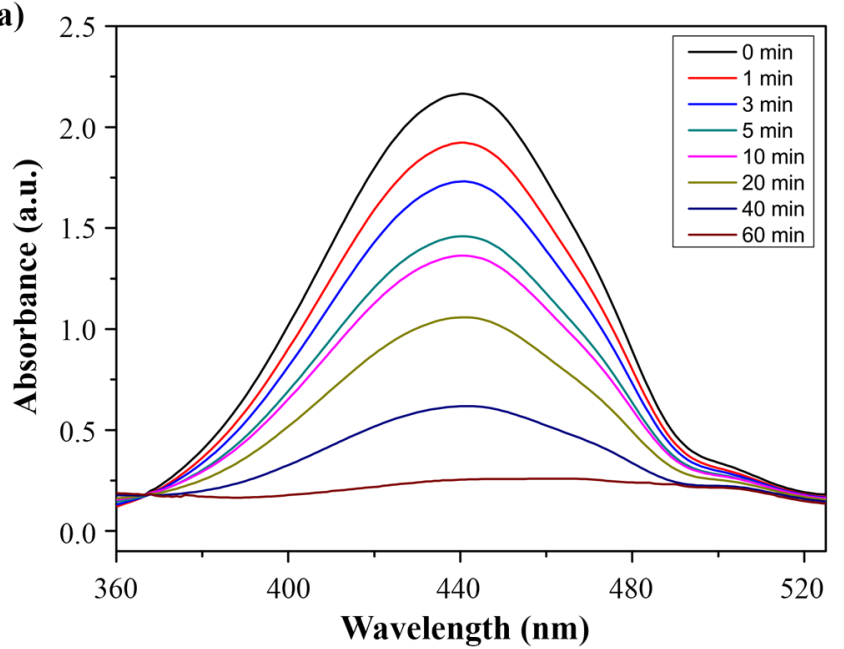

(b)

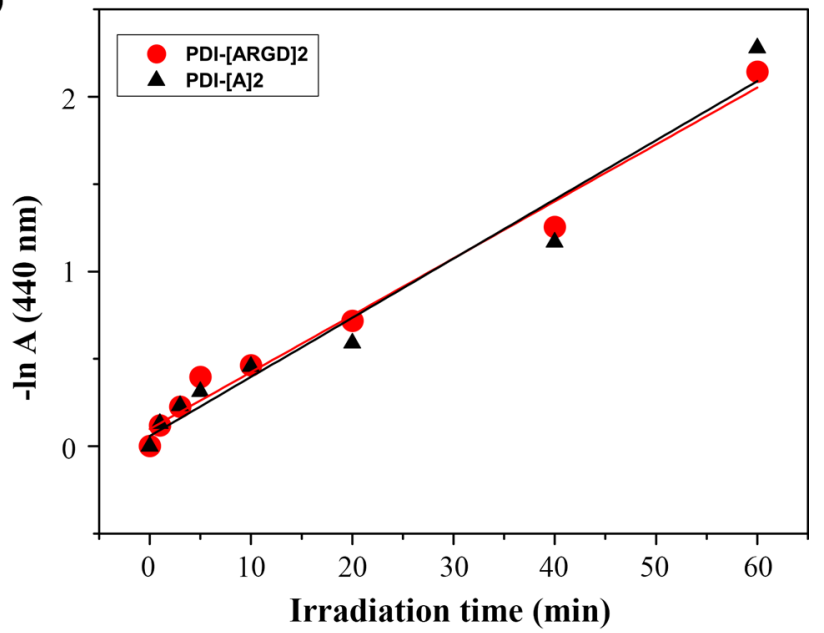

Figure 3. (a) Photochemical oxidation of RNO by the generated ${ }^{1} \mathrm{O}_{2}$ from PDI-[ARGD $]_{2}$ under laser irradiation $\left(532 \mathrm{~nm}, 200 \mathrm{~mW} / \mathrm{cm}^{2}\right) .(\mathrm{b})$ Comparison of the RNO absorbance at $440 \mathrm{~nm}(-\ln A)$ using PDI- $[\mathrm{ARGD}]_{2}$ and PDI- $[\mathrm{A}]_{2}$.
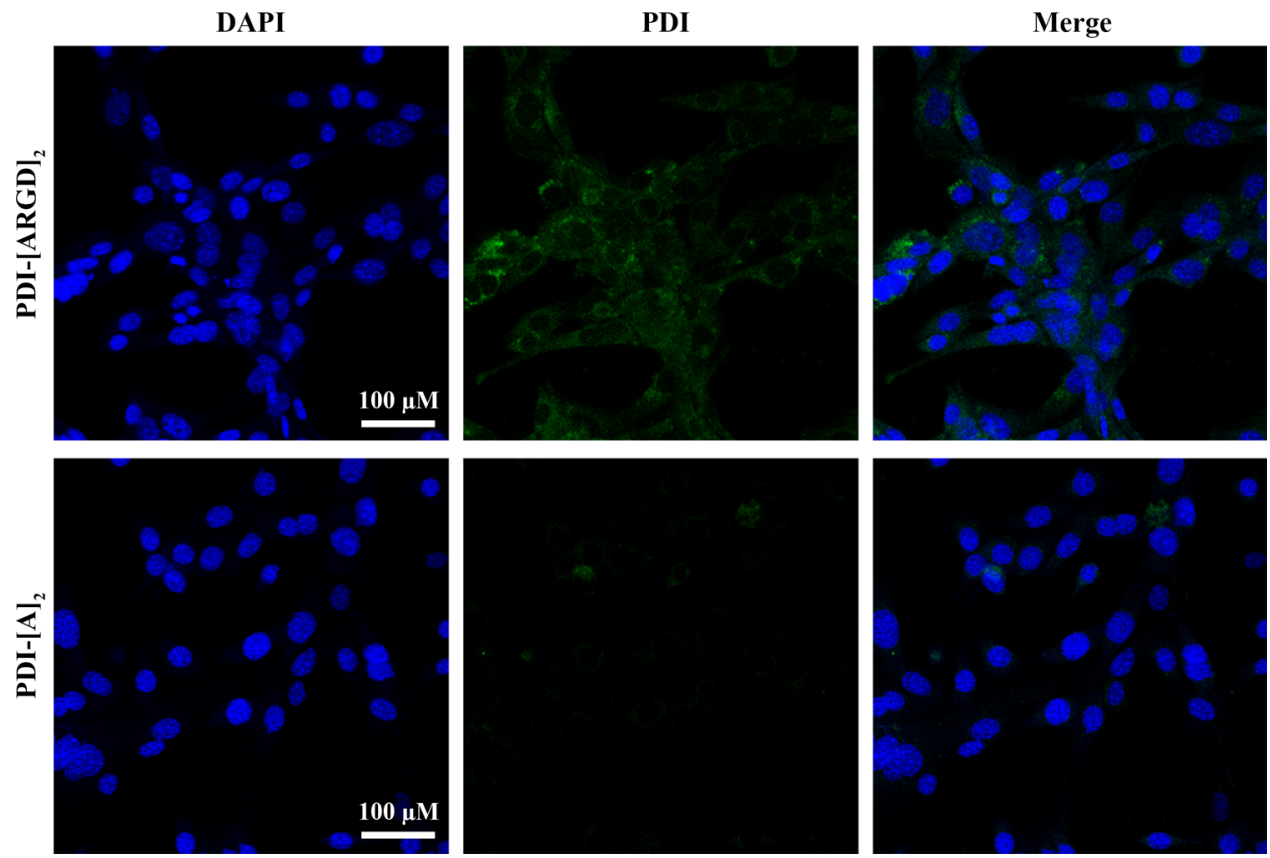

Figure 4. Confocal microscopy images of NIH-3T3 cells after the uptake of PDI-[ARGD $]_{2}$ (top, $0.1 \mathrm{mM}$ ) and PDI-[A] $]_{2}$ (bottom, $\left.0.1 \mathrm{mM}\right)$ (green: PDI, blue: 4',6-diamidino-2-phenylindole (DAPI)).

oxidation (Figure 3a). Furthermore, the ${ }^{1} \mathrm{O}_{2}$ generation ability of PDI- $[\mathrm{ARGD}]_{2}$ and PDI- $[\mathrm{A}]_{2}$ was compared based on the derived slopes of RNO absorbance plots $\left(-\ln A_{440}\right.$ ) (Figure $3 \mathrm{~b}) .^{32}$ As demonstrated, there was no significant influence of the conjugated amino acids on the ${ }^{1} \mathrm{O}_{2}$ generation capacity of PDI. For both compounds, $60 \mathrm{~min}$ laser irradiation was enough for the complete bleaching of RNO. Thus, difference in the cellular uptake would be the discriminating factor for the successful PDT application.

2.5. Cellular Uptake of PDI-[ARGD $]_{2}$ and Cell Viability under Laser Irradiation. First of all, we have confirmed that PDI- $[\mathrm{ARGD}]_{2}$ is a stable compound in the physiological environment. Photoluminescent (PL) stability of PDI$[\mathrm{ARGD}]_{2}$ was well-preserved in a buffer $(\mathrm{pH} 7.4)$ containing $25 \%$ human serum for up to $12 \mathrm{~h}$ (Figure S6). In addition, the compound was noncytotoxic to NIH-3T3 cells in the concentration range of $0.1-100 \mu \mathrm{M}$ (Figure S7). Since the cellular uptake of a photosensitizer is essential for an effective PDT treatment, we studied the cellular uptake of PDI$[\mathrm{ARGD}]_{2}$ by NIH-3T3. As a control, PDI- $[\mathrm{A}]_{2}$ was used which has no integrin binding moiety. As expected, the fluorescence of PDI could be clearly observed in the cytoplasm of NIH-3T3 cells when treated with PDI-[ARGD $]_{2}$, whereas very weak signals of PDI were detected in the PDI- $[\mathrm{A}]_{2}$-treated cells (Figure 4). These results support the fact that the incorporated RGD sequence actively increased the cellular uptake of PDIs, which could allow more effective PDT.

On the basis of the cellular uptake behavior of the PDIs in NIH-3T3 cells, dark toxicity and phototoxicity of the PDI$[\mathrm{ARGD}]_{2}$ and PDI- $[\mathrm{A}]_{2}$ were assessed by the CCK- 8 assay (Figure 5). After treating NIH-3T3 cells with PDI- $[\text { ARGD }]_{2}$ or PDI- $[\mathrm{A}]_{2}$ for $2 \mathrm{~h}$, cell viability was measured with or without 


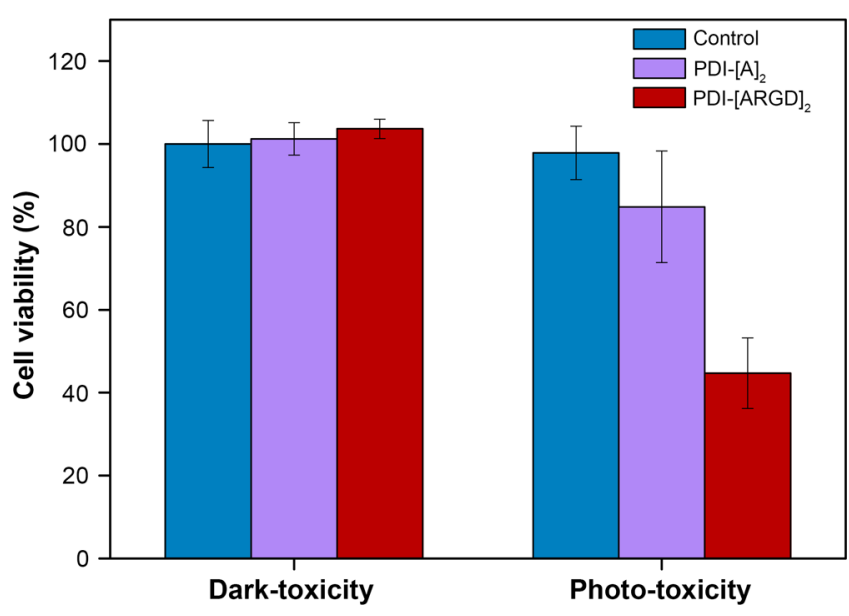

Figure 5. In vitro dark toxicity and phototoxicity of PDI-[ARGD $]_{2}$ $(0.1 \mathrm{mM})$ and PDI-[A $]_{2}(0.1 \mathrm{mM})$ against NIH-3T3 cells. Phosphatebuffered saline (PBS) buffer was used as a control. The error bars indicate the standard deviations based on five samples per group.

laser irradiation under $535 \mathrm{~nm}$. No toxicity was observed in the dark, regardless of the peptide sequence incorporated into PDIs. However, under laser irradiation, PDI-[ARGD $]_{2}$ was demonstrated to be more phototoxic on the NIH-3T3 cells than PDI- $[\mathrm{A}]_{2}$. Since the cellular uptake of PDI- $[\mathrm{A}]_{2}$ was hardly observed, only a moderate level of phototoxicity was observed. However, the phototoxicity of PDI-[ARGD $]_{2}$ was evidently stronger owing to its active targeting ability. Altogether, PDI$[\mathrm{ARGD}]_{2}$ showed reasonable cellular uptake and phototoxicity as an effective PDT agent.

In conclusion, we have developed an efficient synthetic method which can provide a P-PDI bolaamphiphile in high yield $(80 \%)$. By introducing a spacer amino acid, $L$-alanine, into PDA in molten imidazole, the solubility of perylene in organic solvent was improved greatly. Thus, the rest of the amino acid sequences can be easily conjugated to PDI- $[\mathrm{A}]_{2}$ via the SPPS method. As a model peptide sequence, Arg-Gly-Asp (RGD), which can mediate cell attachment, was chosen for cell target therapy. We found that the reaction time and the loading level were the critical factors for obtaining the P-PDI bolaamphiphile in high yield on the CTC resin. Phototoxic effects of PDI$[\mathrm{ARGD}]_{2}$ was tested on cells and was found to exhibit good performance, which suggest that PDI-[ARGD $]_{2}$ has a great potential in the field of photodynamic therapy.

\section{METHODS}

3.1. Materials and Instrument. All starting materials for syntheses were purchased and used without further purification. All reactions were tracked by thin-layer chromatography (TLC) with $0.25 \mathrm{~mm}$ Merck silica gel plates (60F-254) under UV irradiation (UV-lamp, $254 \mathrm{~nm}$ ). The NIH-3T3 cell line, fetal bovine serum (FBS), antibiotics (penicillin-streptomycin), and 4',6-diamidino-2-phenylindole (DAPI) were obtained from Sigma-Aldrich. UV-vis absorbance was measured by using an Optizen 2120 UV (Mecasys, Korea). Fluorescence images were obtained using an LSM 780 confocal laser scanning microscope (Carl Zeiss, Germany). For SPPS, a fritted pressure equalizing (PE) tube (Libra Tube) was used as a reactor, which was shaken by using an SI-600R shaker (JEIO Tech., Korea). The purity of the synthesized peptide was analyzed by using an LCQ LC/MS system (Thermo Finnigan). The silica gel $\mathrm{C}_{8}$ reversed phase (Sigma-Aldrich, 40-63 $\mu \mathrm{m}$ ) was used for column chromatography purification. ${ }^{1} \mathrm{H}$ NMR and ${ }^{13} \mathrm{H}$ NMR spectra were recorded on a Bruker Avance AVIII-500Q spectrometer in deuterated dimethylsulfoxide (DMSO- $d_{6}$, Cambridge Isotope Laboratories, Inc.) with tetramethylsilane as an internal standard. Reverse-phase high-performance liquid chromatography was performed using an Agilent 1260 Infinity LC System with a Kromasil C18 column $(4.6 \times 250 \mathrm{~mm})$. Mass spectra were recorded using an AB SCIEX 3200 QTRAP LC/ MS/MS system combined with an Agilent HPLC. Elemental analyses were performed using an elemental analyzer (Elementar Vario EL III, Germany). Fluorescence images were obtained using a confocal laser scanning microscope (LEICA, Germany). Absorbances for cell cytotoxicity test were measured using a SpectraMax M2 (Molecular Devices).

3.2. Synthesis of Amino Acid-Conjugated Perylene Diimides (PDIs). Glycine ( $2 \mathrm{mmol}), L$-alanine $(2 \mathrm{mmol})$, or $\beta$ alanine $(2 \mathrm{mmol})$ was mixed with $1 \mathrm{mmol}$ of perylene-3,4,9,10tetracarboxylic dianhydride and $2 \mathrm{~g}$ of imidazole in a round bottom flask, respectively. The reaction mixtures were stirred for $30 \mathrm{~min}$ at $130{ }^{\circ} \mathrm{C}$ under a nitrogen atmosphere. After 30 min, the temperature was lowered to $90{ }^{\circ} \mathrm{C}$ and $5 \mathrm{~mL}$ of distilled water (DW) was added. After $10 \mathrm{~min}$, the resulting red solids were filtered to remove the unreacted starting materials. Then, $2 \mathrm{M} \mathrm{HCl}(10 \mathrm{~mL})$ was added to convert the ionized product into a free acid form. Final products were collected by centrifugation and washed with DW several times until the supernatant solution became nonacidic. The collected products were dried in a vacuum oven overnight, yielding dark red solids (Scheme 1a; glycine (1), 88.2\%; $L$-alanine (2), $91.5 \%$; and $\beta$ alanine (3), 89.2\%).

3.3. Synthesis of PDI-[ARGD $]_{2}$ by the SPPS Method. Fluorenylmethyloxycarbonyl (Fmoc)-Asp $(\mathrm{OtBu})-\mathrm{OH}(0.3,0.6$, or $0.9 \mathrm{mmol}$ ) and $\mathrm{N}, \mathrm{N}$-diisopropylethylamine (DIPEA) (4 equiv) in $10 \mathrm{~mL}$ of DMF were introduced into the 2 -CTC resin $(1 \mathrm{~g}, 1.04 \mathrm{mmol} / \mathrm{g})$ and shaken overnight in fritted PE tubes to make different loading levels. After the reaction, the remaining chloride groups in the CTC resin were capped by treating with $10 \mathrm{~mL} \mathrm{MeOH}$ and DIPEA (4 equiv) for $3 \mathrm{~h}$. The loading level was calculated by Fmoc titration. To continue the next amino acid couplings, the resin was treated with $10 \mathrm{~mL}$ of $20 \%$ piperidine/DMF for $20 \mathrm{~min}$ to remove the Fmoc groups. Then, Fmoc-Gly and Fmoc-Arg(pbf) were sequentially coupled to the Asp-loaded resin with hydroxybenzotriazole (HOBT) (2 equiv), 2-(1H-benzotriazol-1-yl)-1,1,3,3-tetramethyluronium hexafluorophosphate (HBTU) (2 equiv), and DIPEA (4 equiv) in DMF for $3 \mathrm{~h}$, and deprotected with $20 \%$ piperidine/DMF for $20 \mathrm{~min}$ after each coupling. The final peptide-coupled resin, $\mathrm{H}-\mathrm{Arg}(\mathrm{pbf})-\mathrm{Gly}-\mathrm{Asp}(\mathrm{tBu})-\mathrm{CTC}$ resin, was divided into four groups (200 $\mathrm{mg}$ each) to find out optimal reaction times and loading levels. The resins were coupled to PDI-[A $]_{2}$ (0.5 equiv) with HOBT (1 equiv), HBTU ( 1 equiv), and DIPEA (2 equiv) in DMF for $30 \mathrm{~min}, 1,2,4$, and $12 \mathrm{~h}$, respectively. The resins were washed with DMF, $\mathrm{DCM}$, and $\mathrm{MeOH}$ until no fluorescence appeared from the washing solution. For on-bead dimerization, the same coupling condition was applied, including HOBT (1 equiv), HBTU (1 equiv), and DIPEA ( 1 equiv) in DMF. The dimerization time was the same as in the previous reaction. The final product was cleaved from the resin by treating it with trifluoroacetic acid (TFA)/triisopropylsilane $/ \mathrm{H}_{2} \mathrm{O} \quad(95: 2.5: 2.5)$ for $1 \mathrm{~h}$ and recovered as red solids after trituration with diethyl ether. The yields and the purities of the products were compared by HPLC and ESI-MS data. For HPLC analysis, a gradient of 
buffer (buffer (A) deionized water containing 0.1\% TFA; buffer (B) acetonitrile containing $0.1 \%$ TFA) with a flow rate of 1.0 $\mathrm{mL} / \mathrm{min}$ was applied as an eluent as shown in Table S1. To find out the swelling effect of the resin on synthesis, different kinds of solvents-DMF and two mixed solvents (THF/DMF and DCM/DMF) were used for SPPS. The loading level and the coupling reaction time were fixed at $0.9 \mathrm{mmol} / \mathrm{g}$ and $2 \mathrm{~h}$, and the results were also compared.

3.4. Purification of PDI-[ARGD $]_{2}$ by Reverse-Phase Silica Gel Column Chromatography. After the structure of each peak was confirmed through HPLC and ESI-MS, C8reverse-phase silica gel column chromatography was applied to purify the final product. A reverse-phase TLC plate was also used to obtain reasonable $R_{\mathrm{f}}$ values for separation. Under $\mathrm{MeCN} / 0.1 \%$ TFA in a $\mathrm{H}_{2} \mathrm{O}(40: 60)$ solvent system, we could obtain reasonable $R_{\mathrm{f}}$ values of the product $(0.44)$ and the byproduct (0.75), which is a single peptide-conjugated PDI. Before separation, a silica gel slurry was prepared by distilled $\mathrm{MeOH}$ to pack the column. After loading the sample, the mobile solvent system was added for separation. Moderate pressure was applied to the column, and two distinct colors from the products were easily recognized during separation. The final product obtained by column chromatography (yield, $60 \%$ ) was confirmed by ESI-MS, ${ }^{1} \mathrm{H}$ NMR (Figure S4), and ${ }^{13} \mathrm{C}$ NMR (Figure S5).

3.5. Singlet Oxygen Generation. Singlet oxygen generation (SOG) was estimated by observing a decrease in the absorbance of the mixed p-nitrosodimethylaniline (RNO) at $440 \mathrm{~nm}$ under $532 \mathrm{~nm}$ laser excitation $\left(200 \mathrm{~mW} / \mathrm{cm}^{2}\right.$, Changchun New Industries Optoelectronics Tech. Co., Ltd., China). The aqueous mixtures for SOG estimation were prepared by mixing $0.21 \mathrm{~mL}$ of PDI-[ARGD $]_{2}$ solutions with $0.11 \mathrm{~mL}$ of RNO solution $(0.12 \mathrm{mM}), 0.7 \mathrm{~mL}$ of histidine solution $(0.03 \mathrm{M})$, and $0.18 \mathrm{~mL}$ of water. Laser excitation at $532 \mathrm{~nm}$ was performed by irradiating the collimated laser beam through the sample. The mixture for SOG estimation was prepared by the same procedure in the case for PDI- $[\mathrm{A}]_{2}$ as well.

3.6. In Vitro Cellular Uptake. NIH-3T3 cell line was maintained in an RPMI-1640 medium supplemented with $10 \%$ FBS and $1 \%$ antibiotic (penicillin-streptomycin) in a humidified $5 \% \mathrm{CO}_{2}$ incubator at $37{ }^{\circ} \mathrm{C}$. The cells were seeded $\left(5 \times 10^{5}\right.$ cells/well $)$ onto $100 \mathrm{~mm}$ dishes with slide glasses at the bottom and allowed to grow until reaching $70 \%$ confluence. After washing with PBS buffer ( $\mathrm{pH} 7.4)$ twice, the cells were incubated in a $7.0 \mathrm{~mL}$ of serum-free medium containing PDI$[\mathrm{ARGD}]_{2}$ and PDI- $[\mathrm{A}]_{2}($ each $100 \mu \mathrm{M})$ for $2 \mathrm{~h}$. The treated cells were washed twice with PBS buffer ( $\mathrm{pH} 7.4$ ), fixed with $4 \%(\mathrm{v} / \mathrm{v})$ paraformaldehyde for $5 \mathrm{~min}$ and stained with DAPI for $3 \mathrm{~min}$ at room temperature. Then, fluorescence images were obtained using a confocal laser scanning microscope.

3.7. Cytotoxicity Test. NIH-3T3 cells were seeded $(1 \times$ $10^{4}$ cells/well) onto 96-well plates and incubated for $24 \mathrm{~h}$. After replacing the culture medium with $200 \mu \mathrm{L}$ of serum-free medium containing $100,10,1$, and $0.1 \mu \mathrm{M}$ of PDI-[ARGD $]_{2}$, the treated cells were incubated for $2 \mathrm{~h}$ at $37{ }^{\circ} \mathrm{C}$. The cells were washed with fresh medium, and each well was treated with 20 $\mu \mathrm{L}$ of CCK- 8 reagent and incubated for $2 \mathrm{~h}$. Subsequently, absorbance at $450 \mathrm{~nm}$ was measured.

3.8. In Vitro Dark and Phototoxicity Assay. NIH-3T3 cells were seeded $\left(1 \times 10^{4}\right.$ cells/well $)$ onto 96 -well plates and incubated for $24 \mathrm{~h}$. After replacing the culture medium with $200 \mu \mathrm{L}$ of serum-free medium containing PDI-[ARGD $]_{2}$ or
PDI- $[\mathrm{A}]_{2}$ (each $\left.1 \mu \mathrm{M}\right)$, the treated cells were incubated for $2 \mathrm{~h}$ at $37{ }^{\circ} \mathrm{C}$. The cells were washed with fresh medium and irradiated with laser $\left(535 \mathrm{~nm}, 200 \mathrm{nW} / \mathrm{cm}^{2}\right.$, each well for 5 $\mathrm{min})$. Then, the cells were further incubated for another $3 \mathrm{~h}$ to assess phototoxicity. For the dark-toxicity test, the cells were prepared following the same procedure without laser irradiation. Then, each well was treated with $20 \mu \mathrm{L}$ of CCK-8 reagent and incubated for $1 \mathrm{~h}$, and then the absorbance at 450 nm was measured.

\section{ASSOCIATED CONTENT}

\section{Supporting Information}

The Supporting Information is available free of charge on the ACS Publications website at DOI: 10.1021/acsomega.8b00040.

Temperature-dependent ${ }^{1} \mathrm{H}$ NMR spectroscopy of PDIamino acid derivatives, HPLC, ESI-MS, ${ }^{1} \mathrm{H}$ NMR, ${ }^{13} \mathrm{C}$ $\mathrm{NMR}$, in vitro PL stability, and cytotoxicity test data of PDI- $[\mathrm{ARGD}]_{2}$ (PDF)

\section{AUTHOR INFORMATION}

\section{Corresponding Author}

*E-mail: yslee@snu.ac.kr. Tel.: 82-2-880-7073. Fax: 82-2-8801604.

ORCID

Sehoon Kim: 0000-0002-8074-1006

Yoon-Sik Lee: 0000-0002-9637-7528

\section{Present Address}

${ }^{\#}$ Nano Systems Institute, Seoul National University, Gwanakgu, Seoul 08826, Republic of Korea (Y.-S.L.).

\section{Author Contributions}

Y.-O.K. and S.-J. P. contributed equally to this work.

\section{Notes}

The authors declare no competing financial interest.

\section{ACKNOWLEDGMENTS}

This work was supported by the Samsung Research Funding Center of Samsung Electronics under project number SRFCMA1401-01.

\section{REFERENCES}

(1) Pass, H. I. Photodynamic therapy in oncology: mechanisms and clinical use. J. Natl. Cancer Inst. 1993, 85, 443-456.

(2) Dougherty, T. J.; Gomer, C. J.; Henderson, B. W.; Jori, G.; Kessel, D.; Korbelik, M.; Moan, J.; Peng, Q. Photodynamic therapy. J. Natl. Cancer Inst. 1998, 90, 889-905.

(3) Dolmans, D. E.; Fukumura, D.; Jain, R. K. Photodynamic therapy for cancer. Nat. Rev. Cancer 2003, 3, 380-387.

(4) Brown, S. B.; Brown, E. A.; Walker, I. The present and future role of photodynamic therapy in cancer treatment. Lancet Oncol. 2004, 5, 497-508.

(5) Agostinis, P.; Berg, K.; Cengel, K. A.; Foster, T. H.; Girotti, A. W.; Gollnick, S. O.; Hahn, S. M.; Hamblin, M. R.; Juzeniene, A.; Kessel, D.; et al. Photodynamic therapy of cancer: an update. $C A$ Cancer J. Clin. 2011, 61, 250-281.

(6) Detty, M. R. Photosensitisers for the photodynamic therapy of cancer and other diseases. Expert Opin. Ther. Pat. 2001, 11, 18491860.

(7) DeRosa, M. C.; Crutchley, R. J. Photosensitized singlet oxygen and its applications. Coord. Chem. Rev. 2002, 233, 351-371.

(8) Detty, M. R.; Gibson, S. L.; Wagner, S. J. Current clinical and preclinical photosensitizers for use in photodynamic therapy. J. Med. Chem. 2004, 47, 3897-3915. 
(9) Karunakaran, S. C.; Babu, P. S.; Madhuri, B.; Marydasan, B.; Paul, A. K.; Nair, A. S.; Rao, K. S.; Srinivasan, A.; Chandrashekar, T. K.; Rao, C. M.; et al. In vitro demonstration of apoptosis mediated photodynamic activity and NIR nucleus imaging through a novel porphyrin. ACS Chem. Biol. 2013, 8, 127-132.

(10) Würthner, F.; Saha-Möller, C. R.; Fimmel, B.; Ogi, S.; Leowanawat, P.; Schmidt, D. Perylene bisimide dye assemblies as archetype functional supramolecular materials. Chem. Rev. 2016, 116, 962-1052.

(11) Wu, J.; Yang, Z.; Jiao, J.; Sun, P.; Fan, Q.; Huang, W. The Synthesis and Biological Applications of Water-Soluble Perylene Diimides. Prog. Chem. 2017, 29, 216-230.

(12) Ma, Y.; Li, X.; Wei, X.; Jiang, T.; Wu, J.; Ren, H. Synthesis and properties of amino acid functionalized water-soluble perylene diimides. Korean J. Chem. Eng. 2015, 32, 1427-1433.

(13) Cao, G.-J.; Rong, R.-X.; Wang, Y.-N.; Xu, Q.; Wang, K.-R.; Li, $\mathrm{X}$.-L. Synthesis and photodynamic therapy of mono-mannose modified perylene bisimide bridged permethyl- $\beta$-CDs. Dyes Pigm. 2017, 136, 569-576.

(14) Chen, C.-Y.; Wang, K.; Gu, L.-1.; Li, H. The study of perylene diimide-amino acid derivatives for the fluorescence detection of anions. RSC Adv. 2017, 7, 42685-42689.

(15) Sun, M.; Müllen, K.; Yin, M. Water-soluble perylenediimides: design concepts and biological applications. Chem. Soc. Rev. 2016, 45, $1513-1528$.

(16) Gallaher, J. K.; Aitken, E. J.; Keyzers, R. A.; Hodgkiss, J. M. Controlled aggregation of peptide-substituted perylene-bisimides. Chem. Commun. 2012, 48, 7961-7963.

(17) Eakins, G. L.; Gallaher, J. K.; Keyzers, R. A.; Falber, A.; Webb, J. E.; Laos, A.; Tidhar, Y.; Weissman, H.; Rybtchinski, B.; Thordarson, P.; et al. Thermodynamic factors impacting the peptide-driven selfassembly of perylene diimide nanofibers. J. Phys. Chem. B 2014, 118, 8642-8651.

(18) Vadehra, G. S.; Wall, B. D.; Diegelmann, S. R; Tovar, J. D. Onresin dimerization incorporates a diverse array of $\pi$-conjugated functionality within aqueous self-assembling peptide backbones. Chem. Commun. 2010, 46, 3947-3949.

(19) Shao, C.; Grüne, M.; Stolte, M.; Würthner, F. Perylene Bisimide Dimer Aggregates: Fundamental Insights into Self-assembly by NMR and UV/Vis Spectroscopy Shao, Changzhun; Gruene, Matthias; Stolte, Matthias; Wuerthner, Frank. Chem. - Eur. J. 2012, 18, 13665-13677.

(20) Pierschbacher, M. D.; Ruoslahti, E. Cell attachment activity of fibronectin can be duplicated by small synthetic fragments of the molecule. Nature 1984, 309, 30-33.

(21) Ruoslahti, E. RGD and other recognition sequences for integrins. Annu. Rev. Cell Dev. Biol. 1996, 12, 697-715.

(22) Hersel, U.; Dahmen, C.; Kessler, H. RGD modified polymers: biomaterials for stimulated cell adhesion and beyond. Biomaterials 2003, 24, 4385-4415.

(23) Park, B.-D.; Lee, Y.-S. The effect of PEG groups on swelling properties of PEG-grafted-polystyrene resins in various solvents. React. Funct. Polym. 2000, 44, 41-46.

(24) Kilmer, S. L.; Anderson, R. Clinical use of the Q-switched ruby and the Q-switched Nd: YAG (1064 nm and $532 \mathrm{~nm}$ ) lasers for treatment of tattoos. J. Dermatol. Surg. Oncol. 1993, 19, 330-338.

(25) Kilmer, S. L.; Lee, M. S.; Grevelink, J. M.; Flotte, T. J.; Anderson, R. R. The Q-switched Nd: YAG laser effectively treats tattoos: a controlled, dose-response study. Arch. Dermatol. 1993, 129, 971-978.

(26) Bouzari, N.; Tabatabai, H.; Abbasi, Z.; Firooz, A.; Dowlati, Y. Laser Hair Removal: Comparison of Long-Pulsed Nd: YAG, LongPulsed Alexandrite, and Long-Pulsed Diode Lasers. Dermatol. Surg. 2004, 30, 498-502.

(27) Rox Anderson, R.; Parrish, J. A. Microvasculature can be selectively damaged using dye lasers: a basic theory and experimental evidence in human skin. Lasers Surg. Med. 1981, 1, 263-276.

(28) Dierickx, C. C.; Grossman, M. C.; Farinelli, W. A.; Anderson, R. R. Permanent hair removal by normal-mode ruby laser. Arch. Dermatol. 1998, 134, 837-842.
(29) Gan, S. D.; Graber, E. M. Laser hair removal: a review. Dermatol. Surg. 2013, 39, 823-838.

(30) Lin, X.; Kurata, H.; Prabhu, D. D.; Yamauchi, M.; Ohba, T.; Yagai, S. Water-induced helical supramolecular polymerization and gel formation of an alkylene-tethered perylene bisimide dyad. Chem. Commun. 2017, 53, 168-171.

(31) Kraljić, I.; Mohsni, S. E. A new method for the detection of singlet oxygen in aqueous solutions. Photochem. Photobiol. 1978, 28, $577-581$.

(32) Mosinger, J.; Mička, Z. Quantum yields of singlet oxygen of metal complexes of meso-tetrakis (sulphonatophenyl) porphine. J. Photochem. Photobiol., A 1997, 107, 77-82. 